\title{
Markers of Alzheimer's Disease in Primary Visual Cortex in Normal Aging in Mice
}

\author{
Luis Fernando Hernández-Zimbrón, ${ }^{1}$ Montserrat Perez-Hernández, ${ }^{1,2}$ \\ Abigail Torres-Romero, ${ }^{1,2}$ Elisa Gorostieta-Salas, ${ }^{3}$ Roberto Gonzalez-Salinas, ${ }^{1}$ \\ Rosario Gulias-Cañizo, ${ }^{1,4}$ Hugo Quiroz-Mercado, ${ }^{1}$ and Edgar Zenteno ${ }^{5}$ \\ ${ }^{1}$ Research Department, Asociación para Evitar la Ceguera en México, "Hospital Dr. Luis Sanchez Bulnes" IAP, \\ 04030 México City, Mexico \\ ${ }^{2}$ Divisón de Ciencias Biológicas de la Salud, Universidad Autónoma Metropolitana, Unidad Iztapalapa, Ciudad de México, Mexico \\ ${ }^{3}$ Neuroscience Division, Institute of Cellular Physiology, UNAM, Ciudad Universitaria, Ciudad de México, Mexico \\ ${ }^{4}$ Cell Biology Department, Centro de Investigación y de Estudios Avanzados del IPN, Ciudad de México, Mexico \\ ${ }^{5}$ Department of Biochemistry, School of Medicine, UNAM, Ciudad Universitaria, México City, Mexico
}

Correspondence should be addressed to Luis Fernando Hernández-Zimbrón; lfhernandez@unam.mx

Received 4 June 2017; Accepted 9 August 2017; Published 12 September 2017

Academic Editor: Anna Di Vito

Copyright (C) 2017 Luis Fernando Hernández-Zimbrón et al. This is an open access article distributed under the Creative Commons Attribution License, which permits unrestricted use, distribution, and reproduction in any medium, provided the original work is properly cited.

\begin{abstract}
Aging is the principal risk factor for the development of Alzheimer's disease (AD). The hallmarks of AD are accumulation of the amyloid- $\beta$ peptide 1-42 (A $\beta 42)$ and abnormal hyperphosphorylation of Tau ( $\mathrm{p}$-Tau) protein in different areas of the brain and, more recently reported, in the visual cortex. Recently, A $\beta 42$ peptide overproduction has been involved in visual loss. Similar to AD, in normal aging, there is a significant amyloid deposition related to the overactivation of the aforementioned mechanisms. However, the mechanisms associated with visual loss secondary to age-induced visual cortex affectation are not completely understood. Young and aged mice were used as model to analyze the presence of $\mathrm{A} \beta 42$, p-Tau, glial-acidic fibrillary protein (GFAP), and presenilin-2, one of the main enzymes involved in $\mathrm{A} \beta 42$ production. Our results show a significant increase of $\mathrm{A} \beta 42$ deposition in aged mice in the following cells and/or tissues: endothelial cells and blood vessels and neurons of the visual cortex; they also show an increase of the expression of GFAP and presenilin-2 in this region. These results provide a comprehensive framework for the role of $A \beta 42$ in visual loss due to inflammation present with aging and offer some clues for fruitful avenues for the study of healthy aging.
\end{abstract}

\section{Introduction}

Traditionally, the aging population has been associated with developed countries, but currently two-thirds of the world's oldest persons live in developing countries, where the elderly population is growing faster than in developed regions.

$\mathrm{AD}$ is the most common cause of dementia in older people, and it is estimated that 27 million people are affected worldwide $[1,2]$. As the life expectancy of the population increases, the number of affected individuals is predicted to present a threefold increase by 2050 [2, 3]. Different risk factors have been associated with the development of $\mathrm{AD}$, such as environmental, dietary, and pathological factors, altered glucose metabolism, chronic inflammation, gender, and oxidative stress. Nevertheless, age continues to be the main risk factor for $\mathrm{AD}$, although early-onset disease can occur before the age of 60 years $[4,5]$.

$\mathrm{AD}$ is a paradigm of a neurodegenerative disorder that is caused by the detrimental progression of age-dependent loss of cognitive function. The hallmarks of this disease are accumulation of amyloid aggregates (also known as amyloid plaques), principally constituted by abnormal local deposits of $\mathrm{A} \beta 42$ in the extracellular brain parenchyma and the hippocampus, as well as the formation of neurofibrillary tangles within the neurons in the aforementioned regions [6]. These neurofibrillary tangles consist of cross-linked 
protein strands that generate a double helix structure; the principal component of these tangles is the pathologically hyperphosphorylated Tau protein [7].

The production of $\mathrm{A} \beta$, a critical event in $\mathrm{AD}$, results from the cleavage of the amyloid precursor protein (APP), whose levels are high in $\mathrm{AD}$. This peptide is toxic and induces several detrimental effects on cells, like cell membrane disruption, excessive production of reactive oxygen species, interactions with several proteins that affect their normal function, synaptic failure, chronic local inflammation, glial hyperactivity, and cell death [8]. These changes have been studied and identified mainly in brain areas such as entorhinal, prefrontal, and visual cortices, hippocampus, and olfactory bulb.

In addition, it has been reported that $\mathrm{AD}$ patients lose certain visual functions that are not correlated to structural damage of the eye but with loss of neurological function. A $\beta 42$ peptide toxicity has been related to several disrupted molecular mechanisms in normal vision; for example, inhibition of long-term potentiation and cognitive processes $[9,10]$ increases the proinflammatory effects in the occipital visual cortex and induces gliosis and apoptosis among other toxic effects. These alterations have been correlated with ophthalmic disorders such as age-related macular degeneration (AMD) and glaucoma [11-13]. However, there is not enough information about these pathological changes in the visual cortex during normal aging.

Aging is accompanied by chronic inflammation, demonstrated by the increase of inflammatory mediators such as cytokines and oxidative stress markers and chronic antigenic stress and influenced by the genetic background [14-16]. Chronic inflammation appears to be involved in the pathogenesis of some age-related diseases such as $\mathrm{AD}$, atherosclerosis, diabetes, age-related macular degeneration, and cancer $[17,18]$. As in Alzheimer's disease, aging is also characterized by the accumulation of A $\beta 42$ in "inflammaging," a term used to highlight the importance of inflammation in many age-associated diseases [19]; as previously mentioned, the presence of $A \beta 42$ is associated with vision loss. The presence of multiple $\mathrm{A} \beta 42$ reservoirs in the eye (especially in the retina and the optic nerve) induces different pathologies that lead to potentially blinding disorders [20]. However, the presence of $\mathrm{A} \beta 42$ in the visual cortex and the role it plays in vision loss, related to normal aging, have not been described.

Brains of 4-month-old and 25-month-old C57BL/6J mice were used as an aging model. Visual cortices (VC) were analyzed to evaluate whether an $\mathrm{AD}$-like pathology develops during normal aging in this area.

Our results demonstrated intracellular accumulation of $\mathrm{A} \beta 42, \mathrm{~A} \beta 42$ deposition in blood vessels, and disturbances in the pattern of $\mathrm{p}$-Tau protein distribution in the VC of 25month-old mice. This murine model also showed overexpression of the enzymes involved in the production of $\mathrm{A} \beta 42$ and an increase in the number of astrocytes expressing GFAP protein in the aged mice compared to the young ones.

\section{Materials and Methods}

2.1. Animal and Animal Care. Young (4-month-old and 25month-old) male C57BL/6J mice were maintained on a 12-hour light/dark cycle in a temperature-controlled room, within a clean air box, and food was provided ad libitum (NutriCubo, Purina, USA). The animals were maintained and treated in accordance with the NORMA Oficial Mexicana NOM-036-SSA2-2002, the National Institutes of Health Guidelines for Animal Treatment, and the Ethics Committee of the Asociación para Evitar la Ceguera en México, "Hospital Dr. Luis Sanchez Bulnes" IAP.

2.2. General Procedure. Mice were randomly separated into two experimental groups ( $n=6$ per group). Group 1 was composed of 4-month-old animals and group 2 was composed of 25-month-old mice.

The visual cortices of control and aged mice were obtained for IMHQ assays. Briefly, six animals from each group were transcardially perfused with $4 \%$ paraformaldehyde (Sigma-Aldrich Chemie, Germany) in $0.1 \mathrm{M}$ phosphate buffer (J.T. Baker, NJ; PB, Tecsiquim; $\mathrm{pH}$ 7.4) for the immunohistochemistry assays. Male 4-month-old and 25-monthold C57BL/6J mice were evaluated in the study. Animals were perfused transcardially with phosphate-buffered saline (PBS) and 4\% (w/v) paraformaldehyde under sedation. The brains were postfixed in $4 \%$ paraformaldehyde for $20 \mathrm{~h}$ and immersed in a $30 \%$ sucrose solution (w/v) in PBS for $24 \mathrm{~h}$.

Coronal sections $(20 \mu \mathrm{m})$ from visual cortex were cut on a freezing microtome (Leica CM3050s) and mounted serially. Slides were used for immunofluorescence detection.

2.3. Immunohistochemistry and Immunofluorescence. Rabbit monoclonal anti-A $\beta 42$ antibody (obtained from Abcam, MA, USA) was used to detect the A $\beta 42$ peptide. Goat polyclonal anti-GFAP and rabbit polyclonal anti-p-Tau and rabbit antipresenilin-2 (PS2) antibodies were from Santa Cruz Biotechnology (CA, USA). Alexa Fluor 594 goat anti-rabbit IgG $(\mathrm{H}+\mathrm{L})$, Alexa Fluor 488 mouse anti-goat IgG $(\mathrm{H}+\mathrm{L})$, Alexa Fluor 488 goat anti-rabbit IgG $(\mathrm{H}+\mathrm{L})$, and Alexa Fluor 594 mouse anti-goat IgG $(\mathrm{H}+\mathrm{L})$ were from Molecular Probes, OR, USA.

For the double immunofluorescence (IF) assays, rabbit monoclonal anti-A $\beta 42 /$ goat polyclonal anti-p-Tau (dilution $1: 100)$ antibodies were used and visualized with Alexa Fluor 594 goat anti-rabbit IgG $(\mathrm{H}+\mathrm{L})$ and Alexa Fluor 488 mouse anti-goat IgG $(\mathrm{H}+\mathrm{L})$. Besides, rabbit monoclonal antiPS2/goat polyclonal anti-p-Tau (dilution 1:100) antibodies were used and visualized with Alexa Fluor 488 goat antirabbit IgG $(\mathrm{H}+\mathrm{L})$ and Alexa Fluor 594 mouse anti-goat IgG $(\mathrm{H}+\mathrm{L})$. Samples were mounted onto glass slides in VECTASHIELD Medium (Vector Laboratories, Burlingame, CA, USA) containing DAPI. Representative brain sections from each group were processed in parallel next; these sections were examined with an Olympus BX41 Microscope (Japan) and photographed with an Evolution-QImaging Digital Camera Kit (Media Cybernetics, Rockville, MD, USA) for DAB reaction and the double IF assays were observed through a Leica DM-LS epifluorescence microscope at 40x and 100x (Leica Microsystems, Wetzlar, GmbH, Germany). The fluorochromes were visualized with their specific filters and analyzed in three channels. 
2.3.1. Image Analysis. Fluorescence pixel intensities were measured in several regions of interest (ROIs) within each image using ImageJ. Average pixel intensities were calculated from five ROIs for measurements in different regions from each image. The measures were realized in six animals per time point. All signal intensities were background-subtracted from the average of three.

2.3.2. Statistical Analysis. All of the data are expressed as mean Chi-square for trends and Fisher's exact tests were used for multiple comparisons. Prism GraphPad software was used (Systat Software, Inc., Point Richmond, CA, USA).

\section{Results}

We studied the deposition of $A \beta 42$, changes in Tau expression patterns, GFAP overexpression, and the enzymes involved in the production of the $\mathrm{A} \beta 42$ peptide in the visual cortex of 4-month-old $(4 \mathrm{M})$ and 25 -month-old $(25 \mathrm{M})$ aged symptomatic mice (C57BL/6J WT). To evaluate the overproduction and accumulation of the $\mathrm{A} \beta 42$ peptide in the $\mathrm{VC}$, we performed double immunofluorescence assays in brain sections derived from control $(4 \mathrm{M})$ and aged mice $(25 \mathrm{M})$. The double IF assays showed qualitative increases in the intracellular accumulation and blood vessel deposition of $\mathrm{A} \beta 42$ (Figures 1 and 2) and an increase in its expression, as well as a change in p-Tau's distribution in the VC (Figures 1, 2 , and 3) of $25 \mathrm{M}$ aged mice.

In order to confirm $\mathrm{A} \beta 42$ deposition in blood vessels, we repeated the IF to detect $A \beta 42$ accumulation in $4 \mathrm{M}$ and $25 \mathrm{M}$ aged mice. Again, there is an increase of $A \beta 42$ in blood vessels of $25 \mathrm{M}$ old mice (Figure 2).

The $\mathrm{A} \beta 42$ peptide is a product of the proteolytic cleavage of amyloid precursor protein (APP). APP's cleavage is done first by beta-secretase, followed by a second cleavage by the gamma-secretase complex. This complex is a multisubunit protease comprised of four components: presenilin-1 and presenilin-2 (PS1 and PS2, resp.), nicastrin, anterior pharynx defective-1 (APH-1), and presenilin enhancer 2 (PEN-2). Among these proteins, PS2 is a transmembranal protein and it has been confirmed as the main enzyme involved in the production of $\mathrm{A} \beta 42$ in $\mathrm{AD}$. To evaluate changes in PS2 expression which could be related to the increase in the production of $\mathrm{A} \beta 42$, we performed IF assays in the same aging model. In these assays, because PS2 is a membranal protein (as mentioned before), we decided to use p-Tau to mark microtubules to identify the localization of PS2.

As shown in Figure 3, there is an increase of PS2 expression and there are changes in the expression pattern of this enzyme in the $\mathrm{VC}$ of aged mice compared to the $\mathrm{VC}$ of young mice. Interestingly, we observed changes in the localization of $\mathrm{p}$-Tau protein in aged mice (white arrows in Figure 3).

As shown in Figure 3, there is an increase of PS2 expression and there are changes in the expression pattern of this enzyme in the VC of aged mice compared to the $\mathrm{VC}$ of young mice. Interestingly, we observed changes in the localization of $\mathrm{p}$-Tau protein in aged mice (white arrows in Figure 3).
To evaluate whether $\mathrm{A} \beta 42$ deposition induces an inflammatory response in aged mice, we performed IF assays to detect astrocytes using a GFAP antibody. GFAP is a commonly used marker for astrocytes, and it has been related to brain inflammation and to the proper functioning of the blood-brain barrier in health. In this aging model, we observed an increase in the number of astrocytes positive to GFAP in $25 \mathrm{M}$ mice (Figure 4). Besides, there were large numbers of astrocytes associated with blood vessels in aged mice.

Finally, to demonstrate these results in a semiquantitative manner, we performed fluorescence intensity quantification on every protein or peptide studied in this report.

As shown in Figure 5, we observed a statistically significant increase in the intracellular $A \beta 42$ peptide (a), p-Tau (b), PS2 (c), and GFAP (d) in the VC of aged mice.

\section{Discussion}

In the present study, we demonstrated that, during normal aging, in mice, there is an increase of $\mathrm{AD}$-like pathological changes, like intracellular accumulation and blood vessel deposition of $\mathrm{A} \beta 42$ in the VC; these increases were correlated with significant overexpression of one member of the gamma-secretase complex (PS2). Besides, GFAP, a common marker for astrocytes, showed an increase in its expression, and the number of GFAP-positive astrocytes also increased, indicating the activation of immunological responses in aged brains.

$\mathrm{AD}$ is a neurodegenerative disease with a complex and progressive pathological phenotype that is initially characterized by hypometabolism and impaired synaptic function and, subsequently, by pathological burden [21]. The $\mathrm{A} \beta 42$ peptide is the pathological hallmark of $\mathrm{AD}$ produced by the sequential cleavage of APP by $\beta$-secretase and the gamma-secretase complex. In contrast, the activation of $\partial$-secretase leads to nonamyloidogenic processing of APP and the generation of truncated nontoxic sAPPa fragments $[5,22,23]$. Neurofibrillary tangles formed by the pathological hyperphosphorylation of Tau protein, an associated-microtubule protein that helps to stabilize microtubules, are the other AD hallmark.

The results presented herein show similar AD pathologic changes and, importantly, this model lacks other factors that could be inducing this pathology. It is important to mention that the amino acid sequence of the $\mathrm{A} \beta 42$ peptide in mice does not form amyloid plaques. However, our results indicate an increase of intracellular $\mathrm{A} \beta 42$ in the $\mathrm{VC}$ of aged mice which could be related to the increased expression of PS2, the main enzyme associated with $\mathrm{A} \beta 42$ production in $\mathrm{AD}$ $[24,25]$, and supported by previous studies that have shown that all the components of the gamma-secretase complex increase under stressful conditions, as in $\mathrm{AD}$ [26].

It has been reported that $\mathrm{A} \beta 42$ can bind to a great number of proteins and to extracellular and intracellular macromolecules that affect normal neuronal function due to increases in the production of hydrogen peroxide, induction of oxidative stress, disturbances in $\mathrm{Ca}^{2+}$ homeostasis, and mitochondrial dysfunction (promoting the opening of the 

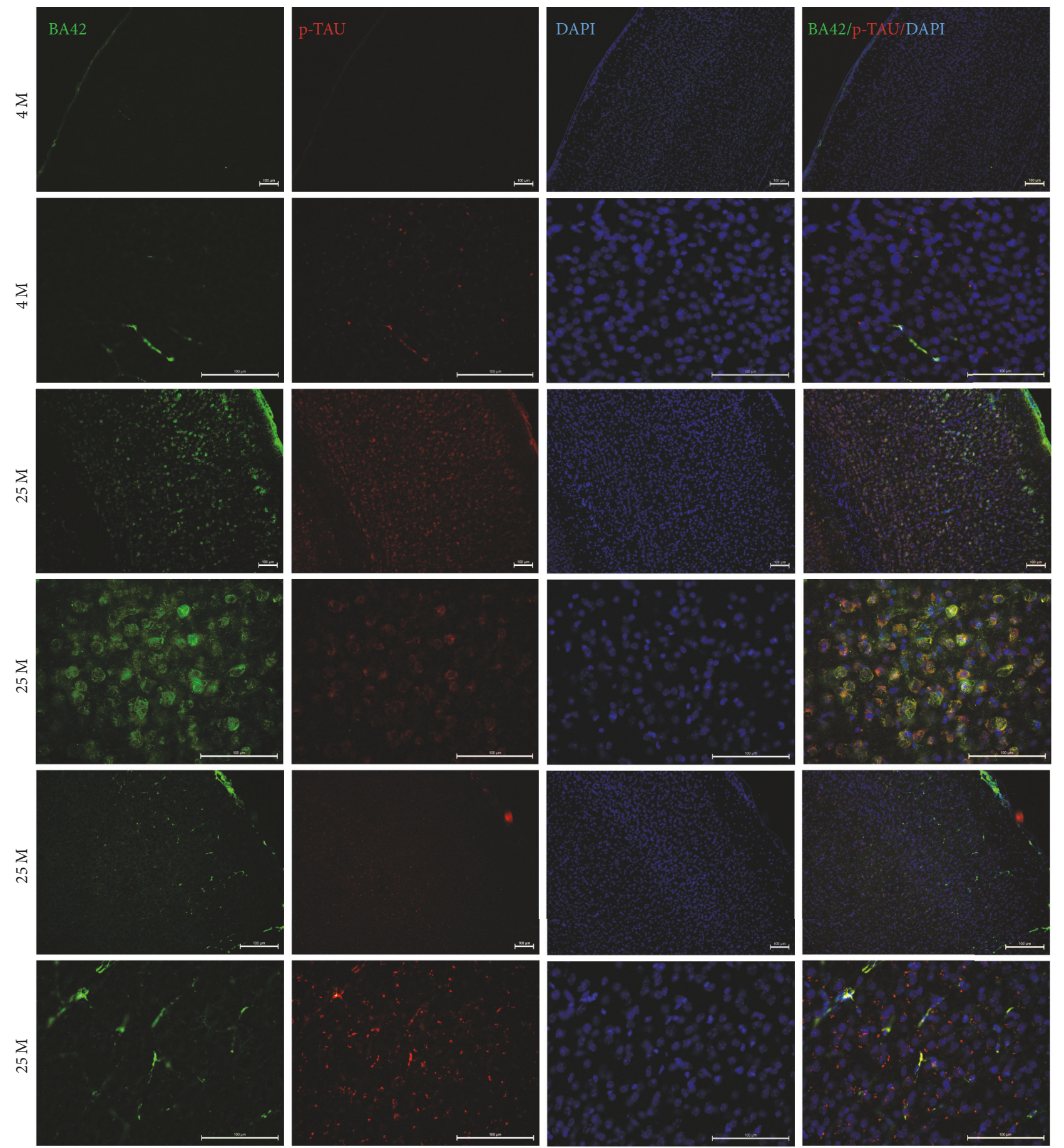

Figure 1: Double IF to detect A $\beta 42$ (green channel) and p-Tau (red channel) in VC of $4 \mathrm{M}$ and $25 \mathrm{M}$ old mice. 15 um thick brain tissue sections of VC from mice were used. DAPI stain for nuclei (DAPI) and Merge are shown. Observe the intracellular accumulation, blood vessel deposition of $\mathrm{A} \beta 42$ peptide, and the increase of $\mathrm{p}$-Tau signal in VC from $25 \mathrm{M}$ old mice. Some tissues of mice show more $\mathrm{A} \beta 42$ deposition in blood vessels (two bottom last lines). Scale bar: $100 \mu \mathrm{m}$.

membrane permeability transition (MPT) pores or disruption of neuronal signal transduction pathways in $\mathrm{AD}[13,19$, 27-30]); however, it is not known whether $\mathrm{A} \beta 42$ accumulation in the VC activates these pathological processes and, as a consequence, they are affecting normal vision. Our results showed an increase of $\mathrm{p}$-Tau, another hallmark of AD. It has been demonstrated that an abnormal increase in p-Tau affects the normal functioning of microtubules, impairs intracellular communication, and, finally, induces cell death [31, 32]. As we observed in Figures 1 and 2, p-Tau not only increases 

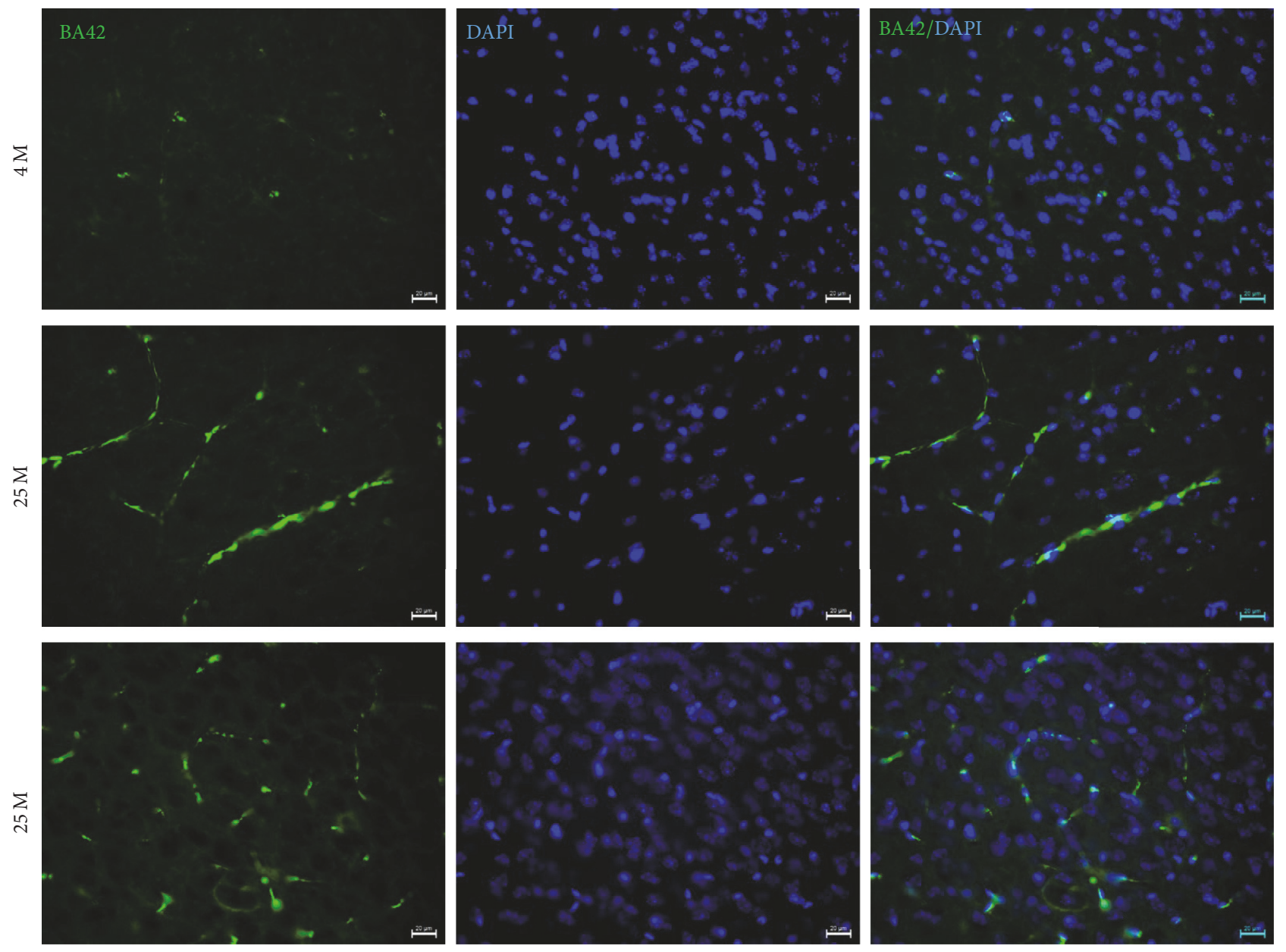

Figure 2: Double IF to detect $\mathrm{A} \beta 42$ in the VC of $4 \mathrm{M}$ and $25 \mathrm{M}$ old mice. 15 um thick brain tissue sections of VC from mice were used. Observe $\mathrm{A} \beta 42$ accumulation in blood vessels in the VC of $25 \mathrm{M}$ old mice. Scale bar: $20 \mu \mathrm{m}$.

its expression but also shows a change of its distribution and localization, suggesting that there may be changes in its intracellular transport in aged mice. More experiments need to be performed to evaluate the impact of this differential expression and localization of $\mathrm{p}$-Tau in the VC during aging.

$\mathrm{AD}$ represents a chronic inflammatory state caused mainly by the presence of the $A \beta 42$ peptide. It has been broadly reported that there is an overreactivity of immune cells, such as astrocytes and microglia, during normal aging and AD [33]. Our results show that some GFAP-positive astrocytes are associated mainly with blood vessels in aged mice, and quantification of GFAP reveals that glial response is also prominent in the VC, as observed in $\mathrm{AD}$. This could be relevant, because disruption of the blood-brain barrier in $\mathrm{AD}$ and activation of proinflammatory mechanisms (like oxidative stress) due to the presence of $\mathrm{A} \beta 42$ have been previously reported. Interestingly, the $\mathrm{A} \beta 42$ peptide accumulates in blood vessels in $25 \mathrm{M}$ old mice. This could suggest that these factors are related, and the presence of growing numbers of astrocytes in blood vessels is a protective response to avoid or repair blood-brain barrier damage caused by the A $\beta 42$ peptide's presence in the aged visual cortex.
There are several inflammatory factors in the aging brain which originate from microglia and astrocytes, as they adopt a senescence-associated secretory phenotype $[19,34]$. Some aging astrocytes release more cytokines, which is consistent with the aforementioned phenotype [35]. However, more studies are needed to demonstrate the production levels of proinflammatory cytokines in the visual cortex of aged mice. Together, these events contribute to neuronal dysfunction in primary visual areas, supposedly protected from betaamyloid deposition [36].

In another way, in order to discuss the translation of our findings and their application in human, it is necessary to mention some interesting points about the different animal models used in aging and AD.

The simplest and best model of aging is an old organism. Mouse is an attractive model for studying mammalian biology due to the genetic manageability of its genome, ease of breeding, and the large amount of available baseline phenotypes; they are relatively economical to maintain for long-term aging studies and, more importantly, they are similar to humans genetically and physiologically $[37,38]$. These similarities and differences between mouse and man 

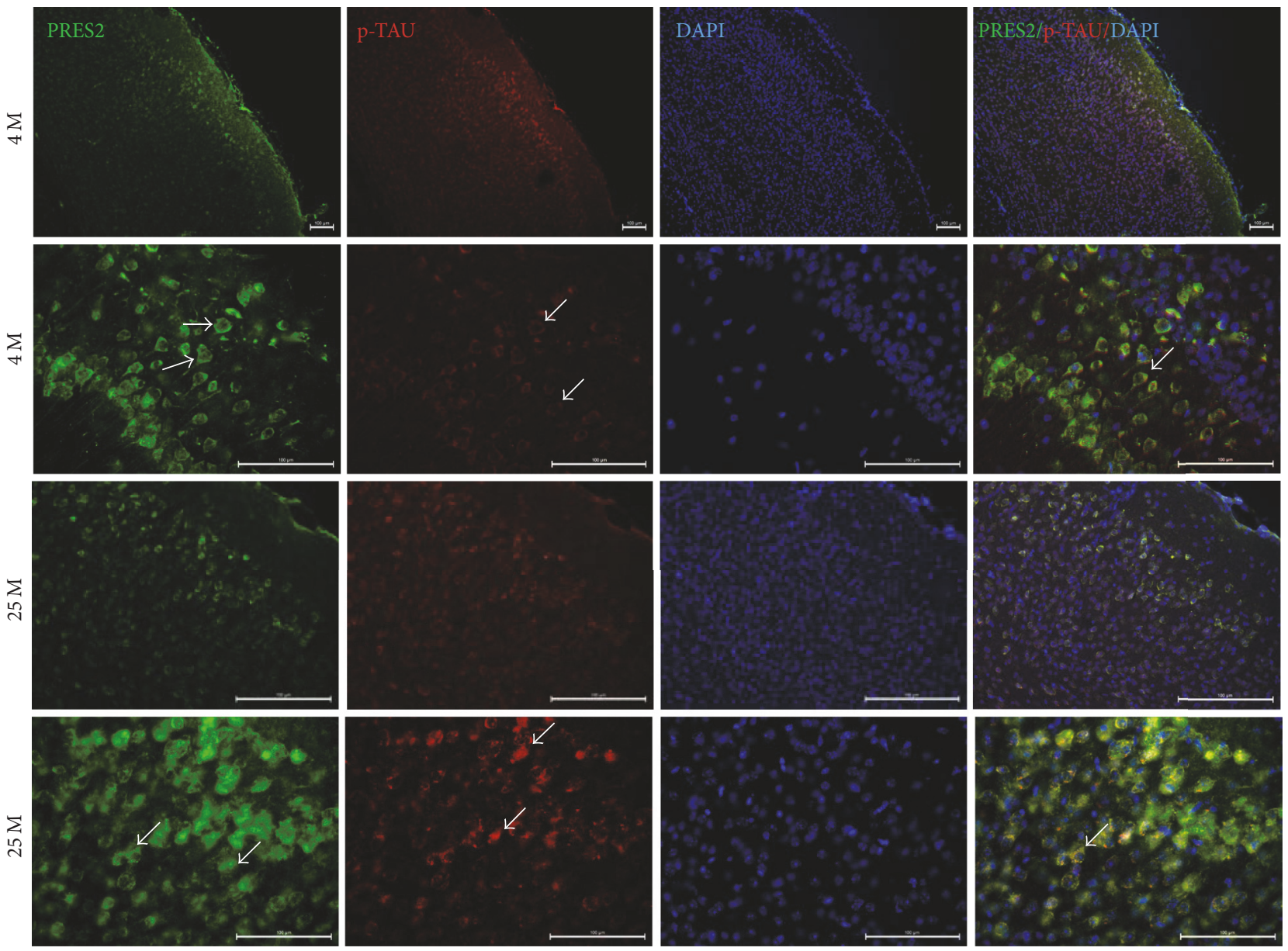

FIgURE 3: Double IF assays to evaluate the overexpression and changes in the localization of presenilin-2. Observe the increase of PS2 expression and the change in the localization of this enzyme in aged mice ( $25 \mathrm{M}$, white arrows). In young mice, PS2 presents a cytoplasmic expression pattern, but, in aged mice $(25 \mathrm{M})$, it is apparently located in the cell membrane (white arrows). Scale bar: $100 \mu \mathrm{m}$.

in relation to studies on aging have been extensively reviewed $[15,39-42]$.

To replicate the pathology of $\mathrm{AD}$ in humans, several animal models of AD pathology have been developed. These mouse models have been useful to study the mechanisms involved in the progression of $\mathrm{AD}$ and to predict outcomes from pharmacological interventions. No animal model fully replicates the pathogenesis and the cognitive deficits observed in human $\mathrm{AD}$ and therefore it is important to understand both the utility and limitations of particular animal models.

According to the recent NIA-AA sponsored consensus reports on three defined stages in a clinical continuum for $\mathrm{AD}$ including preclinical and mild cognitive impairment and dementia, the latter is related to the presence and extent of neuropathological changes of $\mathrm{AD}$ patients observed at autopsy [43, 44]; we present here these neuropathological changes in healthy aging in mice. Our results suggest that these changes could be affecting the normal vision in $\mathrm{AD}$ patients as it has been previously reported.
Although the mouse might not be the perfect model for studying aging, its use as a model of mammalian biology will contribute to gaining important insights into the pathobiology of different diseases, fundamental processes involved in aging, and the relationship between aging and $\mathrm{AD}$. Besides, the validation of these models is totally necessary for a better understanding of the effects of healthy aging and $\mathrm{AD}$ on vision loss to translate these advances to humans.

\section{Conclusions}

Our results show a significant deposition of $\mathrm{A} \beta 42$ peptide and overexpression of other AD markers such as p-TAU and GFAP in the VC of WT 25-month-old mice.

We suggest that the overexpression of presenilin-2 observed in our experiments may be one of the first mechanisms involved in beta-amyloid overproduction in our model and that the mechanisms related to neuronal degeneration downstream of $\mathrm{A} \beta 42$ accumulation could include 


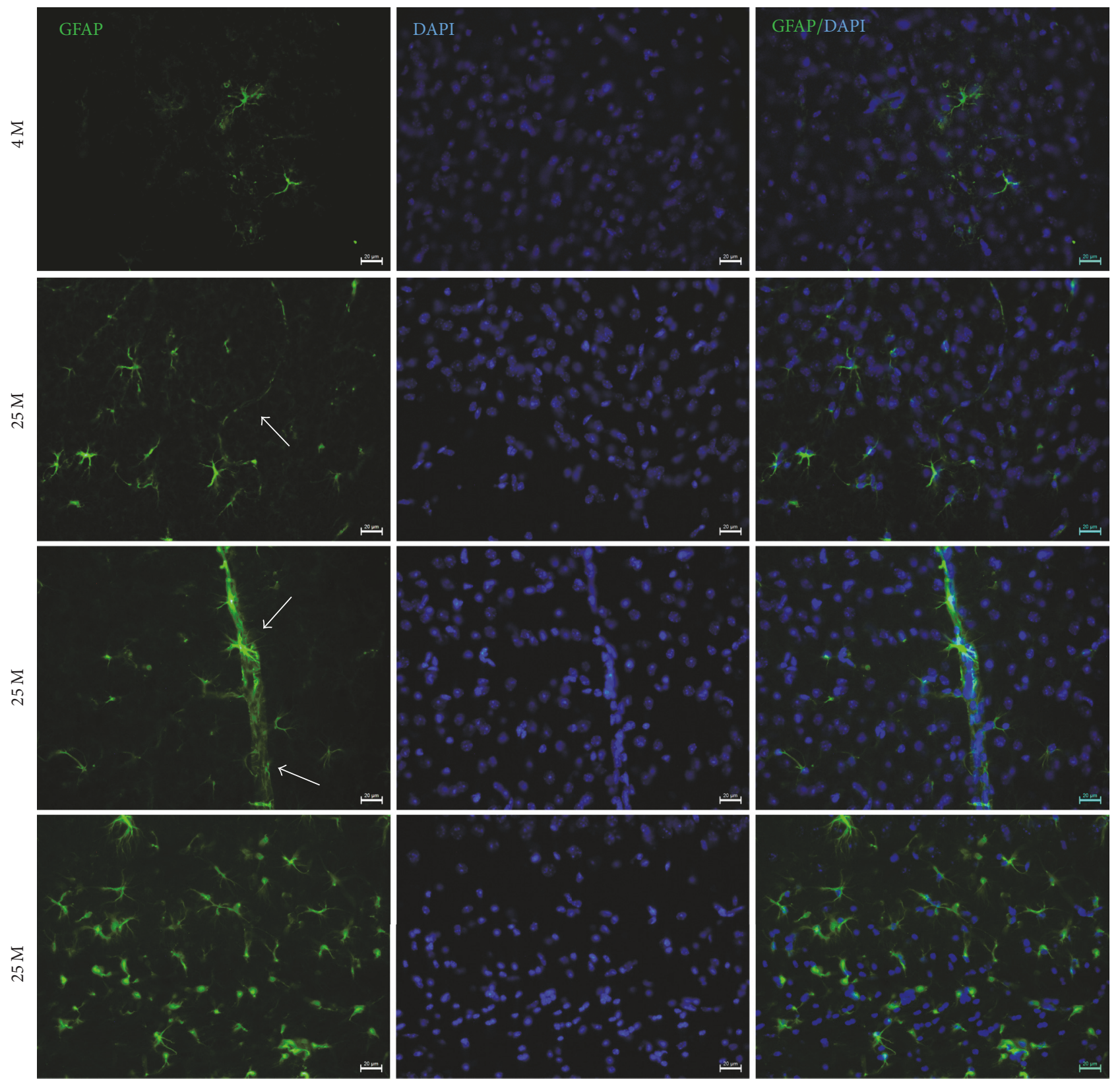

FIGURE 4: Double IF to detect glial fibrillary acidic protein (GFAP), an inflammation marker (green channel), in the VC of $4 \mathrm{M}$ and $25 \mathrm{M}$ old mice. 15 um thick brain tissue sections of VC from mice were used. DAPI stain for nuclei (DAPI) and Merge are shown. Observe GFAP overexpression and an increased number of astrocytes in the VC of $25 \mathrm{M}$ old mice. Scale bar: $20 \mu \mathrm{m}$.

membrane-associated oxidative stress, altered Ca2+ homeostasis, altered energy metabolism, and activation of apoptosis. These findings suggest roles for an alteration of immune responses in the aging process.

Our results demonstrate that aging is possibly related to the activation of the amyloidogenic pathway, which induces $\mathrm{A} \beta 42$ overproduction and intracellular accumulation in visual cortex cells; furthermore, we suggest that $A \beta 42$ accumulation affects several important mechanisms to initialize neurodegenerative processes, such as those occurring in $\mathrm{AD}$, and could be related to vision loss.

Our results aid to understand the correlation between aging and the development of neurodegenerative diseases such as $\mathrm{AD}$, but additional studies are needed to further investigate the effect of the $\mathrm{A} \beta 42$ peptide on the $\mathrm{VC}$ and the retina. 


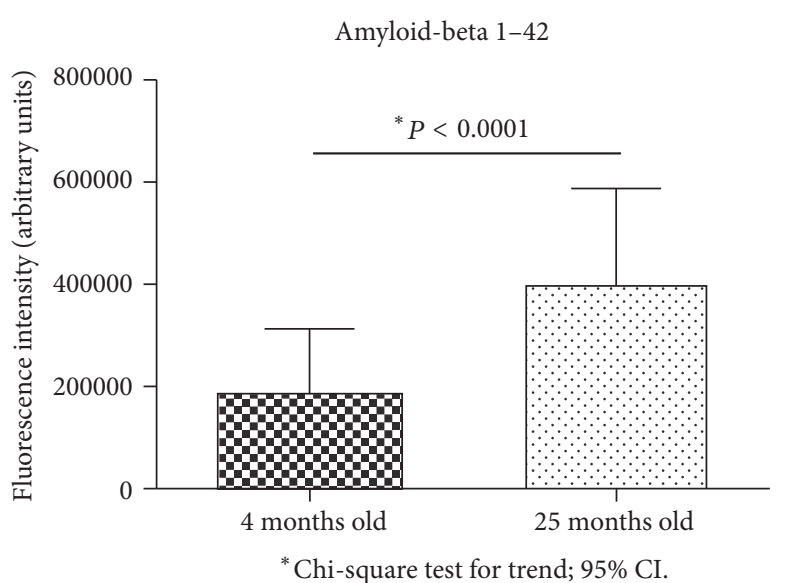

(a)

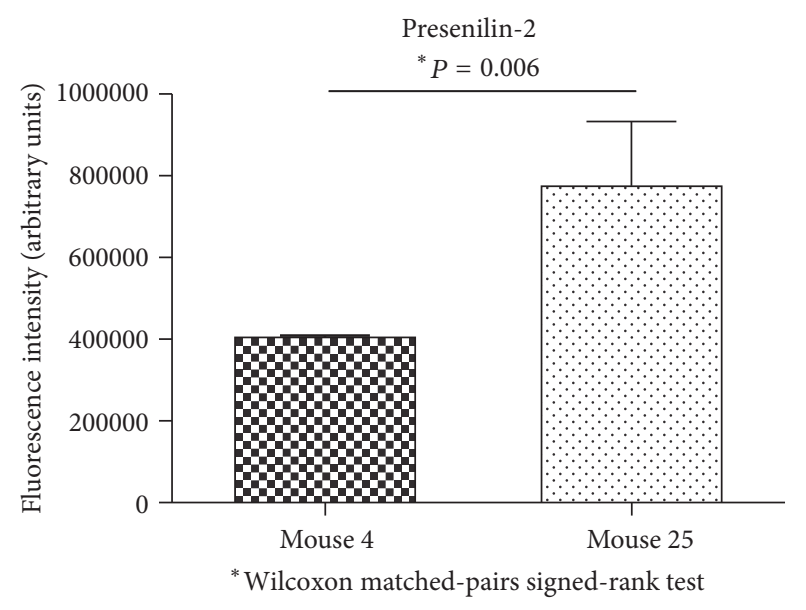

(c)

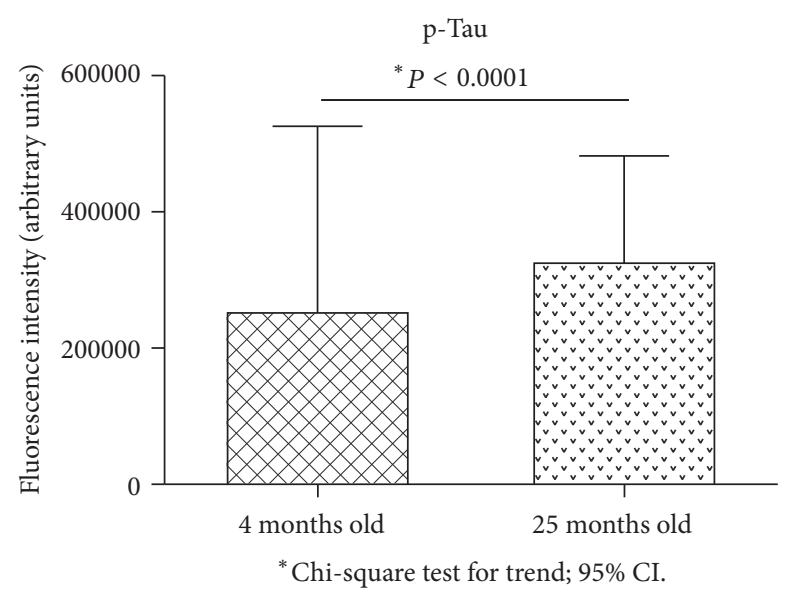

(b)

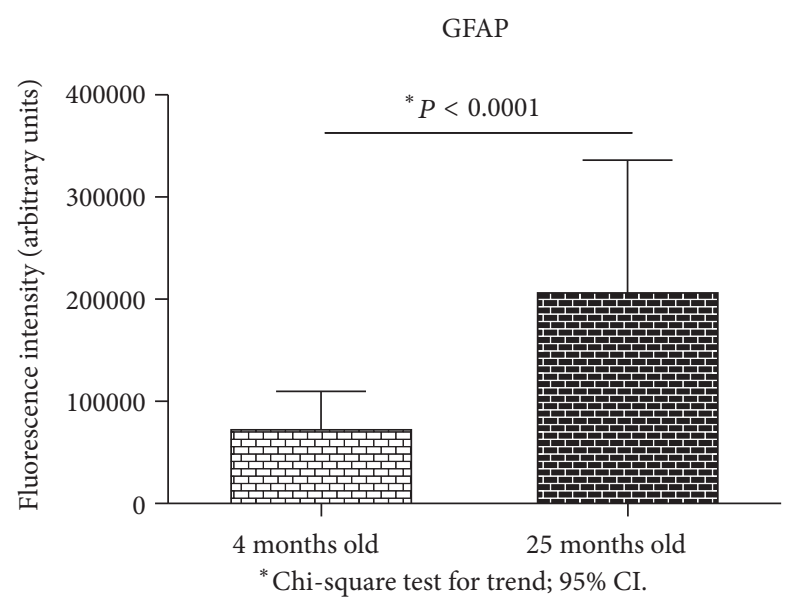

(d)

FIGURE 5: Fluorescence intensities quantification of A $\beta 42$ peptide (a), p-Tau (b), presenilin-2 (c), and GFAP (d) on visual cortex of 4-monthold and 25-month-old mice. For all cases, data were significant. Data are in arbitrary units of fluorescence intensity; $n=6$ animals per group.

\section{Conflicts of Interest}

The authors declare that there are no conflicts of interest.

\section{Acknowledgments}

This work is supported by Asociación para Evitar la Ceguera en México, "Hospital Dr. Luis Sanchez Bulnes” IAP. Thanks are due to Mariana Reyes Peña for technical support.

\section{References}

[1] A. Wimo, L. Jonsson, and B. Winblad, "An estimate of the worldwide prevalence and direct costs of dementia in 2003," Dementia and Geriatric Cognitive Disorders, vol. 21, no. 3, pp. 175-181, 2006.

[2] J. M. Rubio-Perez and J. M. Morillas-Ruiz, "A review: inflammatory process in Alzheimer's disease, role of cytokines," The Scientific World Journal, vol. 2012, Article ID 756357, 15 pages, 2012.
[3] L. E. Hebert, P. A. Scherr, J. L. Bienias, D. A. Bennett, and D. A. Evans, "Alzheimer disease in the US population: prevalence estimates using the 2000 census," Archives of Neurology, vol. 60, no. 8, pp. 1119-1122, 2003.

[4] V. W. Henderson, "Estrogen-containing hormone therapy and Alzheimer's disease risk: Understanding discrepant inferences from observational and experimental research," Neuroscience, vol. 138, no. 3, pp. 1031-1039, 2006.

[5] L. F. Hernández-Zimbrón and S. Rivas-Arancibia, "Deciphering an interplay of proteins associated with amyloid $\beta 1-42$ peptide and molecular mechanisms of Alzheimer's disease," Reviews in the Neurosciences, vol. 25, no. 6, pp. 773-783, 2014.

[6] G. K. Gouras, J. Tsai, J. Naslund et al., "Intraneuronal A $\beta 42$ accumulation in human brain," The American Journal of Pathology, vol. 156, no. 1, pp. 15-20, 2000.

[7] C. Haass and D. J. Selkoe, "Soluble protein oligomers in neurodegeneration: lessons from the Alzheimer's amyloid $\beta$ peptide," Nature Reviews Molecular Cell Biology, vol. 8, no. 2, pp. 101-112, 2007. 
[8] L. Hernández-Zimbrón and F. Selva Rivas-Arancibia, "Deciphering an interplay of protein associated amyloid beta peptide 1-42 and molecular mechanism of Alzheimers disease," Reviews in Neurosciences, p. 25, 2014.

[9] K. Chiu, T.-F. Chan, A. Wu, I. Y.-P. Leung, K.-F. So, and R. C.-C. Chang, "Neurodegeneration of the retina in mouse models of Alzheimer's disease: what can we learn from the retina?" Age, vol. 34, no. 3, pp. 633-649, 2012.

[10] X. Liu and G. Hajnoczky, "Ca2+-dependent regulation of mitochondrial dynamics by the Miro-Milton complex," International Journal of Biochemistry and Cell Biology, vol. 41, no. 10, pp. 19721976, 2009.

[11] A. Kauppinen, J. J. Paterno, J. Blasiak, A. Salminen, and K. Kaarniranta, "Inflammation and its role in age-related macular degeneration," Cellular and Molecular Life Sciences, vol. 73, no. 9, pp. 1765-1786, 2016

[12] H. Yin, L. Chen, X. Chen, and X. Liu, "Soluble amyloid $\beta$ oligomers may contribute to apoptosis of retinal ganglion cells in glaucoma," Medical Hypotheses, vol. 71, no. 1, pp. 77-80, 2008.

[13] M. Pinazo-Duran, R. Gallego-Pinazo, and J. J. García-Medina, "Oxidative stress and its downstream signaling in aging eyes," Clinical Interventions in Aging, vol. 9, pp. 637-652, 2014.

[14] A. Martorana, M. Bulati, S. Buffa et al., "Immunosenescence, inflammation and Alzheimer's disease," Longevity \& healthspan, vol. 1, no. 1, p. 8, 2012.

[15] K. S. Krabbe, M. Pedersen, and H. Bruunsgaard, "Inflammatory mediators in the elderly," Experimental Gerontology, vol. 39, no. 5, pp. 687-699, 2004.

[16] H. Bruunsgaard, "The clinical impact of systemic low-level inflammation in elderly populations. With special reference to cardiovascular disease, dementia and mortality," Danish Medical Bulletin, vol. 53, no. 3, pp. 285-309, 2006.

[17] M. de Martinis, C. Franceschi, D. Monti, and L. Ginaldi, "Inflamm-ageing and lifelong antigenic load as major determinants of ageing rate and longevity," FEBS Letters, vol. 579, no. 10, pp. 2035-2039, 2005.

[18] G. Candore, G. Colonna-Romano, C. R. Balistreri et al., "Biology of longevity: Role of the innate immune system," Rejuvenation Research, vol. 9, no. 1, pp. 143-148, 2006.

[19] T. Wyss-Coray, "Ageing, neurodegeneration and brain rejuvenation," Nature, vol. 539, no. 7628, pp. 180-186, 2016.

[20] L. F. Hernández-Zimbrón, E. Gorostieta-Salas, M. L. DíazHung, R. Pérez-Garmendia, G. Gevorkian, and H. QuirozMercado, "Beta Amyloid Peptides: Extracellular and Intracellular Mechanisms of Clearance in Alzheimers Disease," in In Update on Dementia. InTech, 2016.

[21] J. Yao, S. Chen, Z. Mao, E. Cadenas, and R. D. Brinton, "2-deoxyD-glucose treatment induces ketogenesis, sustains mitochondrial function, and reduces pathology in female mouse model of Alzheimer's disease," PLoS ONE, vol. 6, no. 7, Article ID e21788, 2011.

[22] F. M. LaFerla, K. N. Green, and S. Oddo, "Intracellular amyloid$\beta$ in Alzheimer's disease," Nature Reviews Neuroscience, vol. 8, no. 7, pp. 499-509, 2007.

[23] L. F. Hernandez-Zimbron, J. Luna-Muñoz, R. Mena et al., "Amyloid- $\beta$ peptide binds to cytochrome $\mathrm{C}$ oxidase subunit 1 ," PLoS ONE, vol. 7, no. 8, Article ID e42344, 2012.

[24] L. X. Zhang and X. H. Zhang, "The -secretasecomplex:from structuretofunction," Front. Cell. Neuroscience, 2014.
[25] L. F. Hernandez-Zimbron and S. Rivas-Arancibia, "Oxidative stress caused by ozone exposure induces $\beta$-amyloid 1-42 overproduction and mitochondrial accumulation by activating the amyloidogenic pathway," Neuroscience, vol. 304, pp. 340-348, 2015.

[26] K. J. Young and J. P. Bennett, "The mitochondrial secret(ase) of Alzheimer's disease," Journal of Alzheimer's Disease, vol. 20, no. 2, pp. S381-S400, 2010.

[27] D. A. Butterfield and D. Boyd-Kimball, "Amyloid $\beta$-peptide(142) contributes to the oxidative stress and neurodegeneration found in Alzheimer disease brain," Brain Pathology, vol. 14, no. 4, pp. 426-432, 2004.

[28] X. Huang, R. D. Moir, R. E. Tanzi, A. I. Bush, and J. T. Rogers, "Redox-active metals, oxidative stress, and Alzheimer's disease pathology," Annals of the New York Academy of Sciences, vol. 1012, pp. 153-163, 2004.

[29] M. Blurton-Jones and F. M. LaFerla, "Pathways by which A $\beta$ facilitates tau pathology," Current Alzheimer Research, vol. 3, no. 5, pp. 437-448, 2006.

[30] A. Demuro, I. Parker, and G. E. Stutzmann, "Calcium signaling and amyloid toxicity in Alzheimer disease," The Journal of Biological Chemistry, vol. 285, no. 17, pp. 12463-12468, 2010.

[31] P. S. Aisen, J. Cummings, and L. S. Schneider, "Symptomatic and nonamyloid/tau based pharmacologic treatment for Alzheimer disease," Cold Spring Harbor Perspectives in Medicine, vol. 2, no. 3, Article ID a006395, 2012.

[32] L. Crews and E. Masliah, "Molecular mechanisms of neurodegeneration in Alzheimers disease," molecular genetics, p. q160, 2010.

[33] M. Tobo, "Immunohistochemical study of gliosis in the brain of aged and patients with dementia," Fukuoka Acta Medica, vol. 75, no. 2, pp. 72-88, 1984.

[34] J.-P. Coppé, C. K. Patil, F. Rodier et al., "Senescence-associated secretory phenotypes reveal cell-nonautonomous functions of oncogenic RAS and the p53 tumor suppressor," PLoS Biology, vol. 6, no. 12, pp. 2853-2868, 2008.

[35] A. Salminen, J. Ojala, K. Kaarniranta, A. Haapasalo, M. Hiltunen, and H. A. Soininen, "Astrocytes in the aging brain express characteristics of senescence-associated secretory phenotype," European Journal of Neuroscience, vol. 34, no. 1, pp. 311, 2011.

[36] K. M. Rodrigue, K. M. Kennedy, and D. C. Park, "Beta-amyloid deposition and the aging brain," Neuropsychology Review, vol. 19, no. 4, pp. 436-450, 2009.

[37] N. L. Nadon, "Aged rodents for biogerontology research," Handbook of Models for Human Aging, pp. 393-401, 2006.

[38] M. S. Boguski, “The mouse that roared," Nature, vol. 420, no. 6915, pp. 515-516, 2002.

[39] V. Vanhooren and C. Libert, "The mouse as a model organism in aging research: Usefulness, pitfalls and possibilities," Ageing Research Reviews, vol. 12, no. 1, pp. 8-21, 2013.

[40] J. T. Eppig, J. E. Richardson, J. A. Kadin, M. Ringwald, J. A. Blake, and C. J. Bult, "Mouse Genome Informatics (MGI): reflecting on 25 years," Mammalian Genome, vol. 26, no. 7-8, pp. 272-284, 2015

[41] M. A. Bogue, L. L. Peters, B. Paigen et al., "Accessing data resources in the mouse phenome database for genetic analysis of murine life span and health span," Journals of Gerontology Series A Biological Sciences and Medical Sciences, vol. 71, no. 2, pp. 170-177, 2016. 
[42] C. Pettan-Brewer, M. Treuting, and P., "Practical pathology of aging mice," Pathobiology of Aging Age-related Diseases, vol. 1, no. 1, p. 7202, 2011.

[43] B. T. Hyman, C. H. Phelps, T. G. Beach et al., "National Institute on Aging-Alzheimer's Association guidelines for the neuropathologic assessment of Alzheimer's disease," Alzheimer's and Dementia, vol. 8, no. 1, pp. 1-13, 2012.

[44] MA. Ray, NA. Johnston, S. Verhulst, RA. Trammell, and LA. Toth, "Identification of markers for imminent death in mice used in longevity and aging research," in Journal of the American Association for Laboratory Animal Science, vol. 49, pp. 282-288, 2010. 

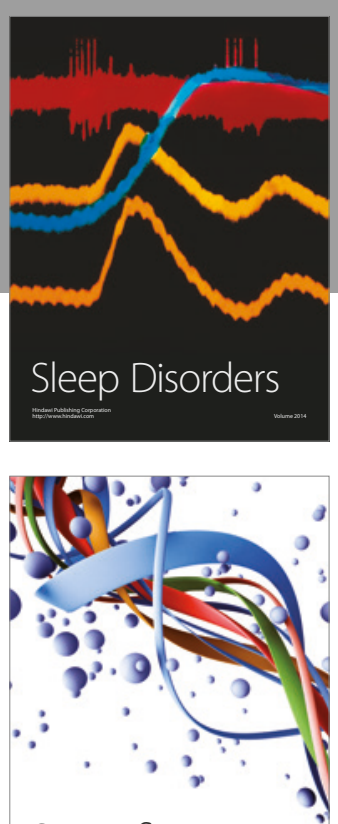

Scientifica
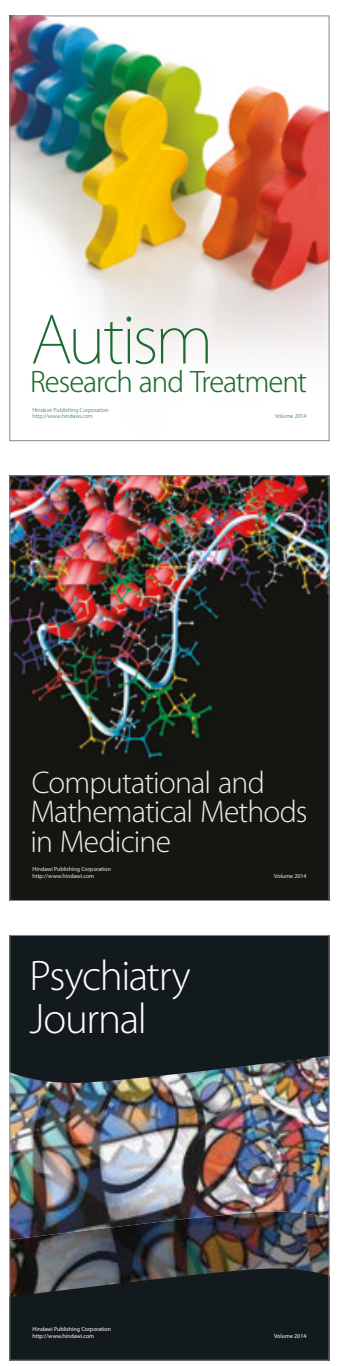
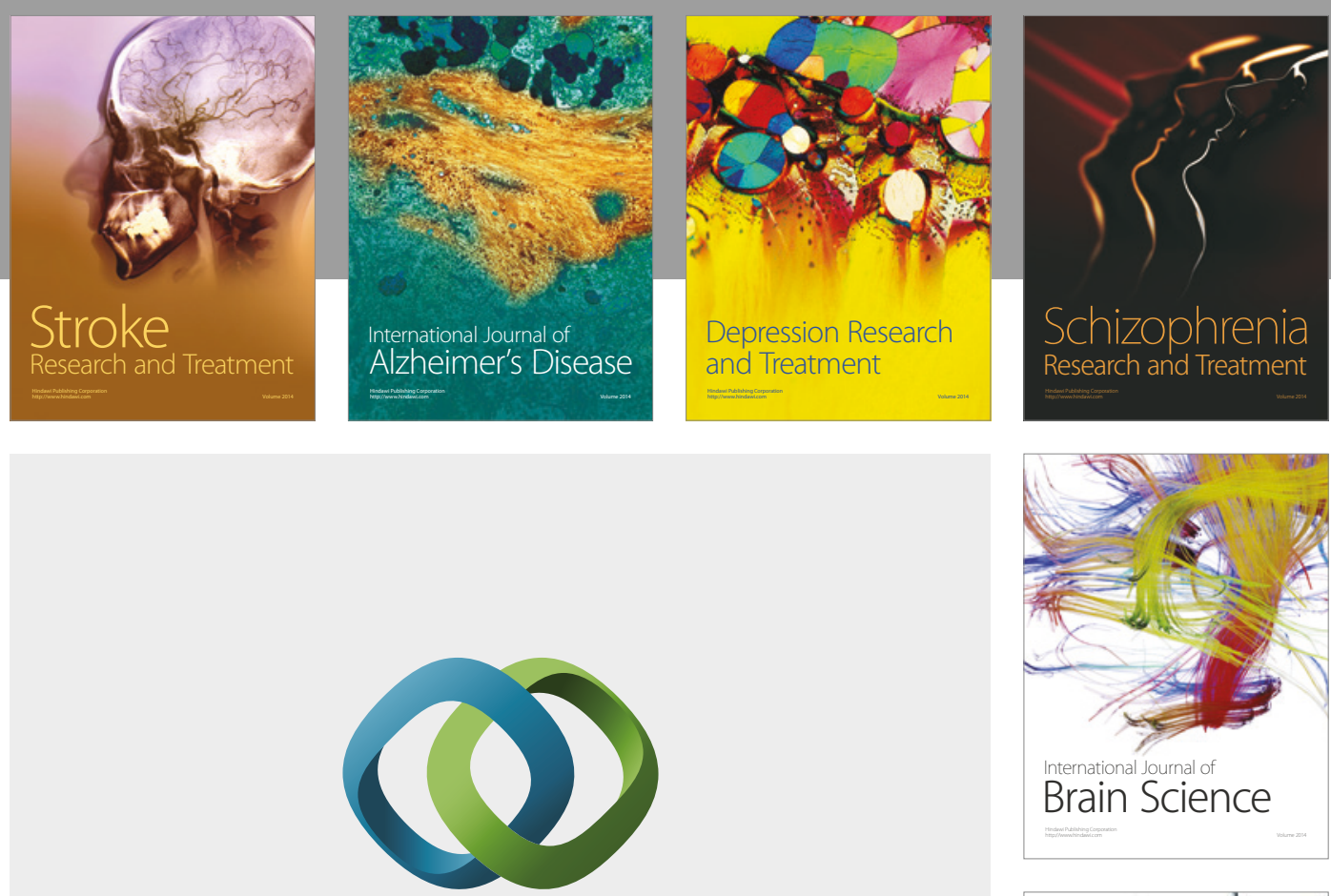

\section{Hindawi}

Submit your manuscripts at

https://www.hindawi.com
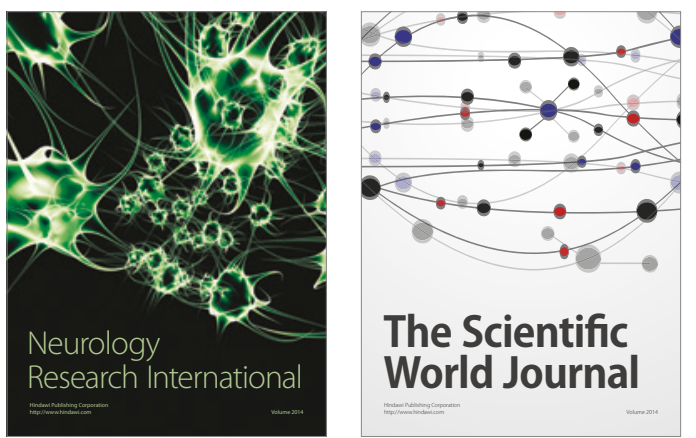

The Scientific World Journal

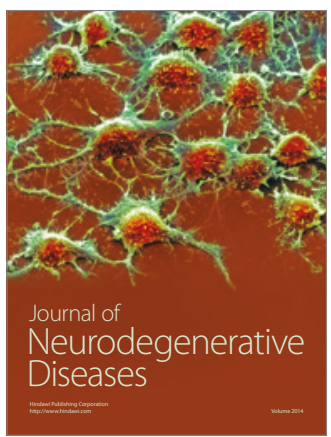

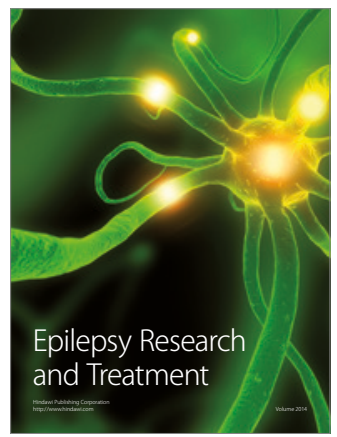

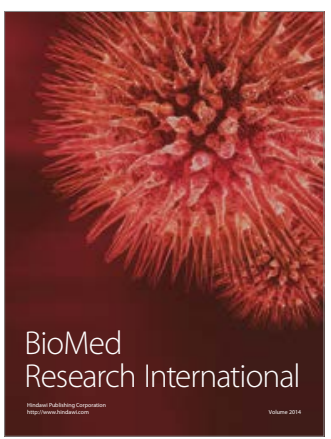

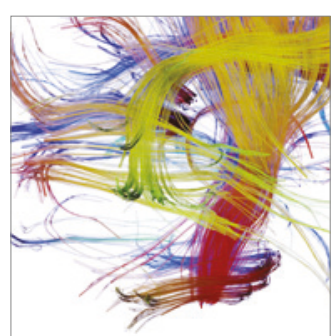

Brain Science

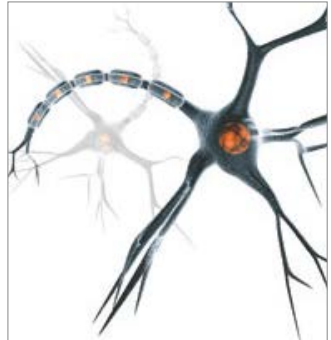

Neural Plasticity
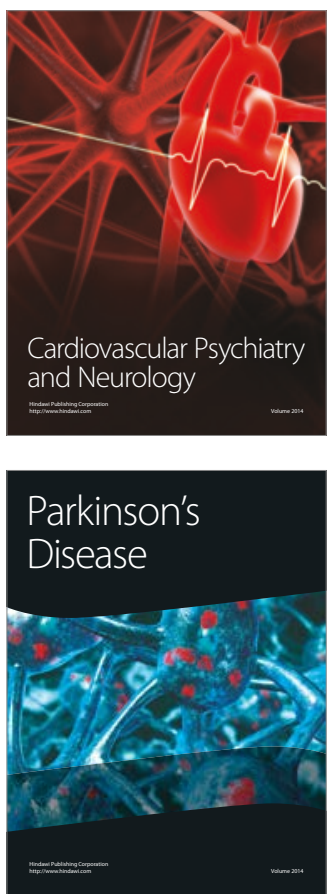